\title{
Power characteristics of the metal compounds formation process during the friction stir welding
}

\author{
Radmir Rzaev ${ }^{1, *}$, Alexander Chularis ${ }^{1}$, and Larisa Semyenova $^{1}$ \\ ${ }^{1}$ Federal Budgetary Governmental Educational Institution of High Education "Astrakhan State University"
}

\begin{abstract}
An influence of the power characteristics on the formation process of the uniform metals compound during the welding with friction stirringis being examined in this article. A dependency between the machine-tool engine power input and the instrument tilt during the FSW for the aluminum alloy AD31, copper alloy M1, titanium alloy OT4-1 and steel St-3 low-alloyed has been explored. A question of the stabilization of power consumption process while the establishment of superplastic condition of welded metal during the FSW has also been reviewed. A dependency revealed between the power characteristics, the geometry of the formation, the rotation speeds, the longitudinal displacement of the tool and its dimensions for fixed values of the parameters during the FSW.
\end{abstract}

\section{Introduction}

More than fifty years has passed since the creation of a variety of the process of friction welding - the way of welding with friction stirring (FSW). However, a numerous publications devoted to various aspects of this process, both of the Russian and foreign researchers, are haven't been advanced very much in the issues of mechanisms of compound formation, and this is already more than two hundred different reports and a dozen of monographs. Although dozens of authors have already proposed various models of the FSW process: there are thermal, thermodynamic, kinetic, deformation, and, more recently, thermal deformation models based on physical principles of superplastic deformations with allowance for the large levels of plastic deformation in the evolution of plastic deformation modes developed by academician V.E. Panin and his co-workers [1-3,9].

The scarcity of information about the energy picture of the FSW process and the multifactor of dependencies of the properties of welded joints, the lack of correlation between the most significant parameters of the FSW process (tool rotation speed, tool tilt, speed of its translational motion along the welded edges - welding speed, axial force on the tool) - all of them have allowed to formulate the purpose of these operations: investigate the quantitative estimates of energy costs accompanying the compounds formation from various metals and OV during the welding on the modes that create and maintain a stable superplastic state in the zone of welded joint formation during the FSW.

\section{Experimental}

The research method consisted in obtaining the FSW compounds on the following coarse-grained sheet materials that could be transferred to the superplastic state. It's a deformed aluminum alloys AD31, technical copper M1, technical $\alpha$-titanium VT1-0, $(\alpha+\beta)$-doped titanium alloy OT4-1, ferrite-pearlite class type St-3 steels, steel \#20, \#09G2S perlite low-alloyed samples, an austenitic high-alloy type 18-10 - steel 12X18H10T, 2-3 mm-thick (see the Table 1)

Table 1. Characteristics of welded materials in FSW [4-6].

\begin{tabular}{|c|c|c|c|c|c|}
\hline $\begin{array}{l}\text { Mark of } \\
\text { alloy }\end{array}$ & $\begin{array}{l}\text { Size of } \\
\text { grains } \\
\text { at } \\
\text { initial } \\
\text { state }\end{array}$ & $\begin{array}{l}\text { Meltin } \\
\mathrm{g} \\
\text { temper } \\
\text { ature } \\
\left(\mathrm{T}_{\max }\right) \text {, } \\
{ }^{\circ} \mathrm{C}\end{array}$ & $\begin{array}{l}\mathrm{SP} \\
\text { manifes } \\
\text { tation } \\
\text { tempera } \\
\text { ture } \\
\left(\mathrm{T}_{\mathrm{sp}}\right) \text {, } \\
{ }^{\circ} \mathrm{C} \\
\left(\mathrm{T}_{\max /} \mathrm{T}_{\mathrm{s}}\right. \\
\text { p) }\end{array}$ & $\begin{array}{l}\text { Recrys } \\
\text { tallizat } \\
\text { ion } \\
\text { temper } \\
\text { ature } \\
\left(\mathrm{T}_{\mathrm{rc}}\right) \text {, } \\
{ }^{\circ} \mathrm{C}\end{array}$ & $\begin{array}{l}\text { The } \\
\text { parameters } \\
\text { of the } \\
\text { manifestati } \\
\text { on process } \\
\text { in the joint } \\
\text { venture } \\
\text { (elongation } \\
\text { coefficient } \\
\text { of velocity } \\
\text { sensitivity) }\end{array}$ \\
\hline $\begin{array}{l}\text { AD31 } \\
\text { (AD1) }\end{array}$ & $\begin{array}{l}\text { NKK } \\
\text { (appro } \\
\text { x. } 0.35 \\
\text { micro } \\
\text { meter) }\end{array}$ & 565 & $\begin{array}{l}270 \\
(0,48)\end{array}$ & 266 & $\begin{array}{l}\text { Elongation } \\
\text { to rupture } \\
320 \%, 0,43\end{array}$ \\
\hline $\begin{array}{l}\text { M1 } \\
\text { copper }\end{array}$ & $\begin{array}{l}\text { NKK } \\
\text { (appro } \\
\text { X. } \quad 0.4 \\
\text { micro } \\
\text { meter) } \\
\end{array}$ & 1083 & $\begin{array}{l}270 \\
(0,25)\end{array}$ & $\begin{array}{l}250- \\
300\end{array}$ & - \\
\hline VT1 & $\begin{array}{l}\text { NKK } \\
\text { (up to } \\
100 \\
\text { nanom } \\
\text { eters) }\end{array}$ & 1820 & $\begin{array}{l}700 \\
(0,38)\end{array}$ & 600 & $\mathrm{~m}=0,4 ; \mathrm{n}=2$ \\
\hline
\end{tabular}

\footnotetext{
* Corresponding author: $\underline{\text { radmir.82@mail.ru }}$
} 


\begin{tabular}{|c|c|c|c|c|c|}
\hline OT4-1 & $\begin{array}{l}\text { MKK } \\
\text { (appro } \\
\text { x. } \quad 1 \\
\text { micro } \\
\text { meter) }\end{array}$ & 1760 & $\begin{array}{l}860 \\
(0,49)\end{array}$ & 880 & - \\
\hline Steel 20 & $\begin{array}{l}\text { MKM } \\
\text { (appro } \\
\text { x. 6-8 } \\
\text { micro } \\
\text { meters } \\
\text { ) }\end{array}$ & 1520 & $\begin{array}{l}730 \\
(0,48)\end{array}$ & 760 & $\begin{array}{l}\text { Elongation } \\
\text { to rupture } \\
320 \%\end{array}$ \\
\hline $\begin{array}{l}18 . \mathrm{Cr}- \\
10 \mathrm{Ni}- \\
0.7 \mathrm{Ti}- \\
0.6 \mathrm{Mn}- \\
0.8 \mathrm{Si}- \\
0.12 \mathrm{C} \\
(12 \mathrm{X} 18 \mathrm{H} \\
10 \mathrm{~T})\end{array}$ & - & 1550 & $\begin{array}{l}780 \\
(0,51)\end{array}$ & 780 & $\begin{array}{l}\text { Max } \\
\text { elongation } \\
220 \% \text {, } \\
8 \times 10-3\end{array}$ \\
\hline
\end{tabular}

The welding was performed on a vertically milling machine equipped with a special tool made of sintered hard alloy. The tool had a Morse cone №1 on the mounting side in the drive head of the machine, this cone has smoothly passed into a cylinder, performing the function of a shoulder with a diameter of $14 \mathrm{~mm}$. The shoulder's end surfacewas made in the form of an inverse cone. In the center of the tool, a pin was placed on its axis in the form of a truncated cone with diameters of $2 / 6 \mathrm{~mm}$ and a length along the generatrix equal to the thickness of the parts to be welded. Butt welded joints were welded at a speed of $900 \mathrm{rpm}$ at the speed of longitudinal movement along the edges (welding speed $20 \mathrm{~mm} / \mathrm{min}$ ), the magnitude of the axial force on the tool, taking into account the properties of the welded metals 4-8 kgs.

\section{Results and Discussion}

When a rotating tool pin enters into the surface layers of welded materials, a friction of the pin and end of the shoulder occurs at the contact point in the first seconds of the process, a heat flux appears as a result of the dryfriction process of these parts of the tool with the weld metal. At the structural-microscale level, surface grains are involved in plastic deformation, which is realized due to the motion of sliding of lattice dislocations due to the presence of a strain gradient [11]. However, in largecrystal metals, most of the dislocations are blocked by the Cottrell and Suzuki atmospheres, as a result of which their start is difficult and for the propagation of plastic deformation sources of mobile dislocations are required, such as the large-angle grain boundaries and their triple junctions. The launch of the latter is carried out by means of a tool inserted into the metal to be welded, by means of which elastically deformable grains adjacent in the layer and in depth are involved in plastic deformation, providing expansion of the zone of plastic deformation to the deep layers of the metal located at the structuralmesoscopic scale level [9]. Owing to the deepening of the rotating and moving along the edges of the tool pin, several mesozones of plastic deformation localization are formed along the thickness of the welded plates and the expansion of mesozones to the entire cross section or thickness of the welded parts $[9,11,12]$. This stage characterizes the transition of local plastic deformation from the mesoscale to the macroscale level, that is, to the completion of the stage of macroplastic deformation. The transition to the structural-mesoscale level, when conglomerates and grain blocks are deformed together due to the launch of rotational mechanisms of plastic deformation and the transition to the mechanism of adhesion friction. As a result of these processes, the temperature increases in a welding zone, and the main powers of superplasticity - grain boundary diffusion [6, 7] and grain-boundary slip activated by it - begins to function [4-5, 11,12].

To gain the information about energy inputs at different stages of welded joint formation process, the value of the power consumed by the electric motor of the machine during the welded joints formation from metals, alloys at different angles of instrument tilt and the similar rates of rotating, the geometry the tool was oscillated.

Taking into account the foregoing, the curve describing the changes in energy consumption for the different stages of the compounds formation in FSW has three typical energy distribution regions (Fig. 1).

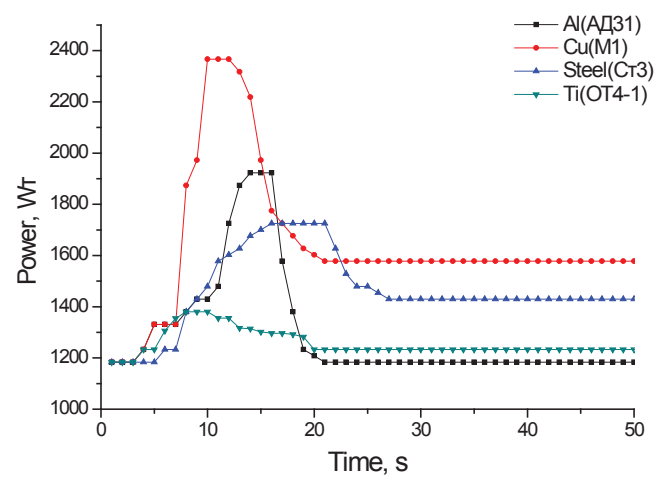

Fig. 1. Dependence between the power input during the FSW from time for AD31, M1, OT4-1, St-3 (tilt angle $1^{\circ}$ )

The first one is the left, increasing, responsible for energy consumption during the logon period. Interacting parts and sources of "dry" friction at the micro- and first meso-scale levels of plastic deformation.

The second, medium, steeply dipping, demonstrates the onset of high levels at high temperatures, especially in the zone of pin, plastic deformation and transition to the superplasticity state and thermal stabilization of the welded joint. The third is the straight section of the curve parallel to the abscissa axis in the course of the welded FSW connections formation process in the established regime of superplasticity at the present macroscopic level (over the entire thickness of the welded parts), the level of plastical deformation with economical and stable FSW mode.

The described nature of the energy change during the welded FSW connections formation was established during the welding of AD31 (AD1) aluminum alloy, M1 copper alloy, welding the steels of different structural classes (St-3, steel 20, steel 12X18H10T), VT1-0 technical alloy and pseudo- $\alpha$ OT4-1 titanium alloy, Fig.2 (all metals are welded at the tool tilt at $3^{\circ}$ ). 


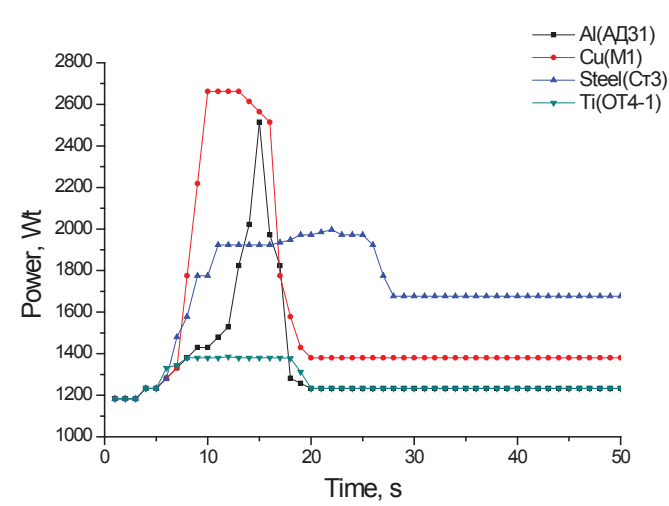

Fig. 2. Dependence between the power input during the FSW from time for AD31, M1, OT4-1, St-3 (tilt angle $3^{\circ}$ )

Experimental metals and alloys used in the studies are representatives of a large range of structural ferrous and non-ferrous metals, differing in mechanical and thermophysical properties and, most significantly, in temperatures of transition to the state of superplastic flow, Table 1 [4-5,8-12].

As follows from the data analysis shown in Fig. 1 and 2, an important parameter of the FSW process is the tool axis angle tilt from the vertical by the "backward angle", since its efficiency determines the conversion of the frictional friction energy into thermal energy, the magnitude of the plastic flow of the solid metal (alloy) in the welding direction, the amount of plastificine under the action of a rotating pin of welded metal, which takes part in the welded seam geometry formation, including penetration through the thickness, and its scaling.

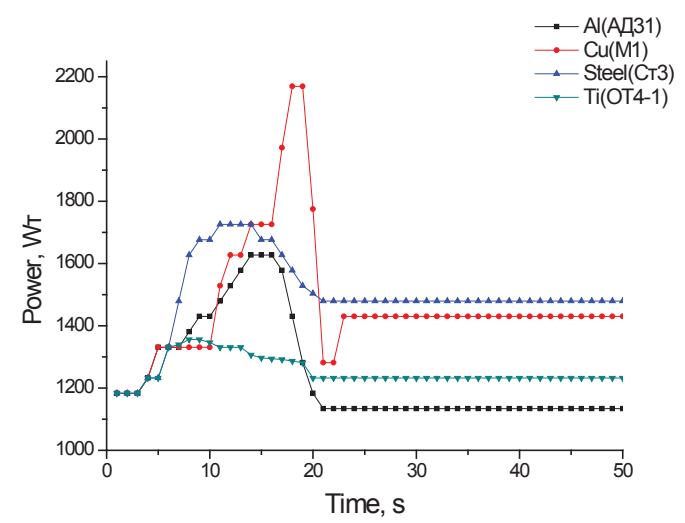

Fig. 3. Dependence between the power input during the FSW from time for AD31, M1, OT4-1, St-3 (tilt angle $5^{\circ}$ ).

In the practice of FSW, various researchers have used the tilt angles from one to five degrees. Measurements of energy consumption at the indicated angles of attack, Fig. 3 with identical values of the remaining parameters of the FSW process when aluminum, copper, steel and titanium were combined, showed that the regularity of the change in energy consumption differs in the initial stages of the FSW process in the form of durations and amplitudes of the fixing energy of the first and second stages until the process stability is achieved. In the third stage, the difference is manifested only in the absolute values of power costs. This can be probably explained by the kinetics of overcoming various mesoscale levels of plastic deformation on all experimental materials due to different values of the viscosity and stresses of the plastic flow of the welded materials that are established after reaching the superplastic transition temperature [4-5].

The analysis of the relative values of energy consumption in the FSW of aluminum, copper steels and titanium showed at first glance a paradoxical result with respect to titanium. Figs. 2 and 3, a reduction in the total energy consumption compared to other metals and alloys studied. But if we take into account the basic mechanisms responsible for the transition to the superplastic state, then it should be taken into account that, in contrast to other metals, where in addition to dynamic continuous recrystallization, anomalous and / or collective recrystallization, and in the transition to the mesoscale level of plastic deformation, and grain-boundary slip, processes (of small crystallographic shifts throughout the volume of the material) of a limited atom displacement by less than $20 \%$ of crystalline grid parameter, which can be observed during the twinning and polymorphous $(\beta \leftrightarrow$ $\left.\alpha^{\prime}\left(\alpha^{\prime \prime}\right)\right)$ transformations occurring in titanium alloys [1012]. As a result of these transformations, the structure of the titanium alloy becomes more dispersed, which increases the superplasticity effect due to the activation of intergrain sliding $[8,10-12]$.

At the same time, the increased energy consumption in the FSW of copper (Fig. 4) is probably due to significant kinematic viscosity, heat capacity, thermal conductivity, tendency to collective and even anomalous recrystallization, and increased values of the magnitude of plastic flow stress that are capable of removing material in the welding zone from the superplasticity regime $[9,4-$ 5].

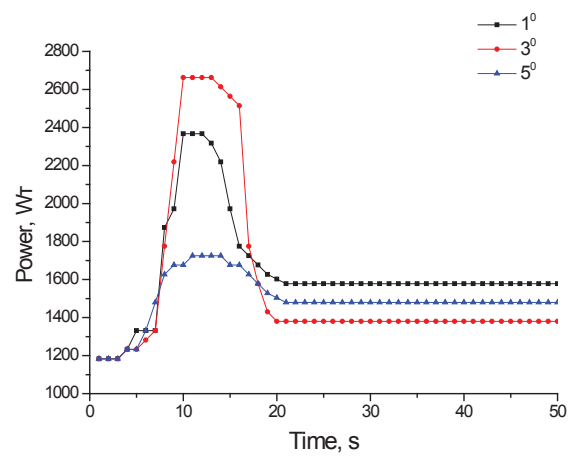

a)

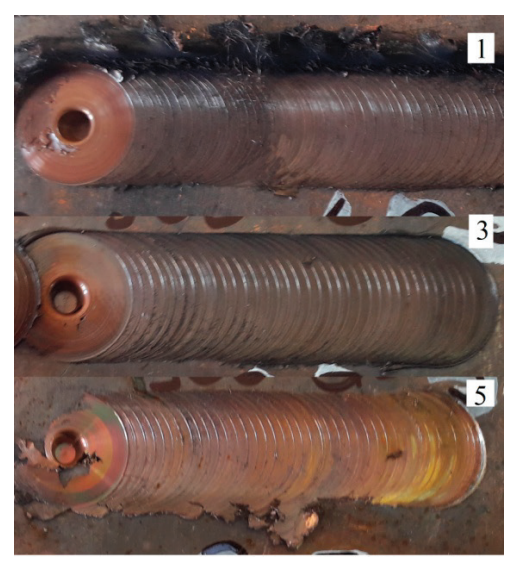

b) 


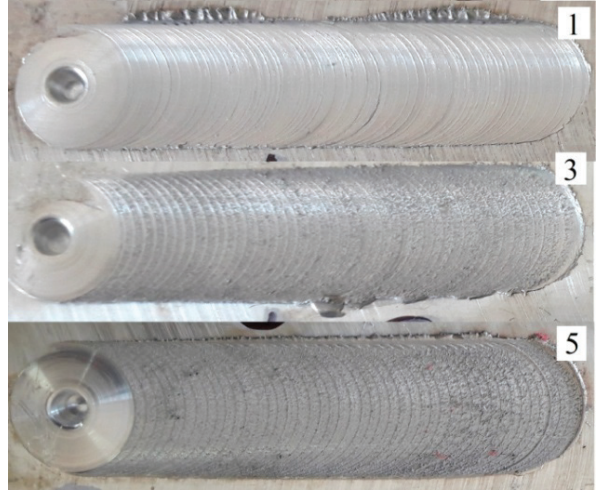

c)

Fig. 4. Dependence between machine-tool power consumption in the FSW from time (a) and the appearance of the welded samples of copper M1 (b) and AD31 (c) alloys for various tool angle tilts.

The geometry of the welded joints, the height of the reinforcement and the character of their scaling together with the state of the underside, the strength at break (on aluminum АД31- 200, on copper M1- 235, carbon steels - 380, titanium alloys- $420 \mathrm{MPa}$ ) are testifying about their satisfactory quality.

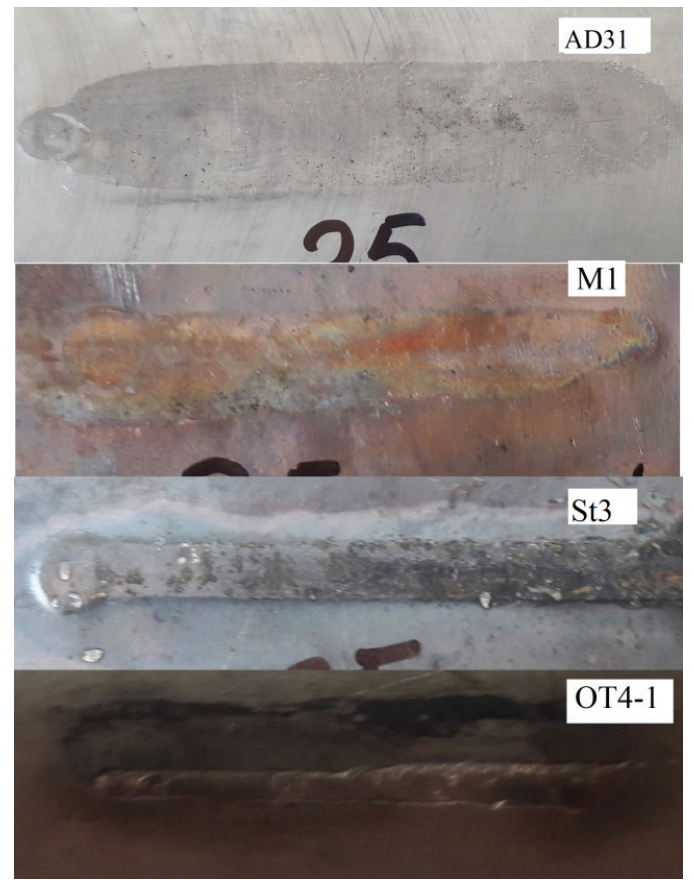

Fig. 5. The reverse side of the aluminum (AD31), copper (M1), steel (St.3) and titanium (OT4-1) alloys (tilt angle is $3^{\circ}$ ).

\section{Conclusions}

Thus, we can formulate the following conclusions:

1. For power consumption, the FSW cycle for all the studied metals has two regions: a starting cycle with a duration of up to $15-20 \mathrm{~s}$. With a maximum power consumption, and steady, characterized by a constant value of power consumption, which are proportional to the stresses of the plastic flow of welded metals in the superplasticity regime.
2. With identical FSW conditions, the tendency of energy costs reduction is evident in connection with multiple mechanisms of plastic deformation manifestation and propagation during the weld formation and energy consumption increase under conditions of increased kinematic viscosity, heat capacity, thermal conductivity and plastic flow stresses.

3. Experimentally established a weakly proportional dependence of energy costs on the tool tilt angle and a rational tilt angle of three degrees is determined.

\section{References}

1. A.V. Panin, Scale levels of deformation in the surface layers of loaded solids and thin films, The dissertation author's abstract on competition of a scientific degree of the doctor of physical and mathematical sciences, Tomsk, (2009).

2. V.E. Panin, V.A. Likhachyov, Y.V. Grinyaev, Structure levels of deformation of solids (Nauka, Novosibirsk, 1985)

3. V.E. Panin, V.E. Egorushkin, A.V. Panin, The nature of localization of plastic deformation of solids, Physical Physics Magazine. 77, 8 (2007)

4. O.A. Kaybishev, Plasticity and superplasticity of alloys (Metallurgiya, Moscow, 1975)

5. O.A. Kaybishev, Superplasticity of industrial alloys (Metallurgiya, Moscow, 1984)

6. Yu.R. Kolobov, R.Z. Valiev, G.P. Grabovetskaya et al., Grain-boundary diffusion and properties of nanostructured materials (Nauka, Novosibirsk, 2001)

7. G.P. Grabovetskaya, Grain-boundary diffusion and creep of submicrocrystalline metallic materials obtained by intensive plastic deformation methods, Author's abstract. dis. to the soot. uch. art. doct. fizmat. sciences, Tomsk, (2008)

8. S.S. Manokhin, Regularities of phase and structural transformations in an unalloyed titanite of mari VT10 . Author's abstract. dis. to the soc. art. cand. tech. sciences, Belgorod, (2012)

9. T.V. Cherkasova, The dislocation structure of polycrystalline $\mathrm{Cu}-\mathrm{Al}$ and $\mathrm{Cu}-\mathrm{Mn}$ alloys and the ratio of the physics of plastic deformation. Author's abstract. dis. to the soc. art. cand. fiz-mat. sciences, Tomsk (2016)

10. A.A. Babarenko, I.V. Egiz, A.I. Khorev et al., Superplasticity of titanium alloys of different classes. Metallurgy and heat treatment of metals, 6 (1995)

11. E.F. Dudarev, G.P. Pochivalova, Yu. R. Kolobov, et al., Microplastic deformation of submicrocrystalline titanium at room and elevated temperatures, Izv. Higher Education, Physics, 55, 7 (2012)

12. E.F. Dudarev, G.P. Pochivalova, Yu. R. Kolobov, et al., Effect of deep plastic deformation and subsequent annealing on true grain-boundary slip in coarsegrained and submicrocrystalline titanium, Physical mesomechanics, Special. Issue 7 (2004) 